\title{
Stimulation of TLR4 by LMW-HA Induces Metastasis in Human Papillary Thyroid Carcinoma through CXCR7
}

\author{
Shipeng Dang, ${ }^{1}$ Yongde Peng, ${ }^{2}$ Lei Ye, ${ }^{3}$ Yanan Wang, ${ }^{4}$ Zhongqing Qian, ${ }^{5}$ \\ Yuqing Chen, ${ }^{5}$ Xiaojing Wang, ${ }^{5}$ Yunzhi Lin, ${ }^{5}$ Xiaomei Zhang, ${ }^{5}$ Xiyan Sun, ${ }^{6}$ \\ Qiong Wu, ${ }^{1}$ Yiji Cheng, ${ }^{1}$ Hong Nie, ${ }^{4}$ Min Jin, ${ }^{1}$ and Huanbai $\mathrm{Xu}^{2,4,5}$ \\ ${ }^{1}$ Institute of Health Sciences, Shanghai Institutes for Biological Sciences, Chinese Academy of Sciences \& \\ Shanghai Jiao Tong University School of Medicine (SJTUSM), 225 South Chongqing Road, Shanghai 200025, China \\ ${ }^{2}$ Department of Endocrinology and Metabolism, Shanghai Jiaotong University Affiliated First People's Hospital, \\ 100 Haining Road, Shanghai 200080, China \\ ${ }^{3}$ Department of Endocrinology and Metabolism, Ruijin Hospital, SJTUSM, 197 Ruijin 2nd Road, Shanghai 200025, China \\ ${ }^{4}$ Shanghai Institute of Immunology, Institutes of Medical Sciences, SJTUSM, 280 South Chongqing Road, Shanghai 200025, China \\ ${ }^{5}$ Department of Endocrinology and Metabolism, The First Affiliated Hospital of Bengbu Medical College and \\ Anhui Clinical and Preclinical Key Laboratory of Respiratory Disease, The First Affiliated Hospital of Bengbu Medical College, \\ 287 Changhuai Road, Bengbu 233004, China \\ ${ }^{6}$ Cancer Hospital, HeFei Institutes of Physical Science, Chinese Academy of Science, 350 Shushan Lake Road, HeFei 230031, China
}

Correspondence should be addressed to Hong Nie; hnie0823@aliyun.com, Min Jin; mjin@sibs.ac.cn and Huanbai Xu; huanbaixu@126.com

Received 9 August 2013; Accepted 12 October 2013

Academic Editor: Marco Antonio Velasco-Velázquez

Copyright (C) 2013 Shipeng Dang et al. This is an open access article distributed under the Creative Commons Attribution License, which permits unrestricted use, distribution, and reproduction in any medium, provided the original work is properly cited.

In inflammatory sites, high molecular weight hyaluronan fragments are degraded into lower molecular weight hyaluronan fragments (LMW-HA) to regulate immune responses. However, the function of LMW-HA in PTC progression remains to be elucidated. In this study, we found that receptor of LMW-HA, TLR4, was aberrantly overexpressed in PTC tissues and cell line W3. Exposure of W3 cells to LMW-HA promoted cell proliferation and migration via TLR4. Knockdown of TLR4 has provided evidence that TLR4 is essential for LMW-HA-induced CXCR7 expression, which is responsible for LMW-HA-induced proliferation and migration of W3 cells. In tumor-bearing adult nude mice, stimulation of LMW-HA on W3 cells promotes CXCR7 expression in tumor masses $(P=0.002)$ and tumor growth $(P<0.001)$. To further confirm our findings, we investigated the clinicopathologic significance of TLR4 and CXCR7 expression using immumohistochemistry in 135 human PTC tissues and 56 normal thyroid tissue samples. Higher rates of TLR4 (53\%) and CXCR7 (24\%) expression were found in PTC tissues than in normal tissues. Expression of TLR4 or CXCR7 is associated with tumor size and lymph node metastasis. Therefore, LMW-HA may contribute to the development of PTC via TLR4/CXCR7 pathway, which may be a novel target for PTC immunomodulatory therapy.

\section{Background}

Papillary thyroid cancer (PTC) is the most prevalent thyroid cancer and represents 70 to $80 \%$ of all thyroid cancers [1]. Incidence of thyroid cancer has increased rapidly in the past 15 years the increase in incidence is almost exclusively attributable to papillary thyroid cancer [2]. Metastasis is the most important biological characteristic of PTC. That is, PTC has a tendency to spread into lymphatic channels and metastasize to regional lymph nodes at a high frequency.

It is known that inflammation plays critical roles in the development of cancers including PTC. It has been reported that T cells, B cells, and NK cells are frequently found within and surrounding primary thyroid tumor [3]. French et al. revealed that PTC patients with tumor-associated lymphocytic infiltration presented more aggressive disease when 
compared with patients with concurrent thyroiditis or without lymphocytic infiltration [4], suggesting the presence of a local inflammatory response in PTC.

The extracellular matrix is important for tumor cell behavior. Hyaluronan (HA) is a polysaccharide normally expressed in the extracellular matrix of connective, neural, and epithelial tissues [5]. Under physiological conditions, HA is primarily distributed in connective tissue with many other proteins to form a large and complicated network that maintains the space between cells $[5,6]$. The native, high molecular weight form (HMW-HA) is composed of repeating disaccharide units of $\mathrm{N}$-acetylglucosamine and glucuronic acid $(4 \times$ $10^{2}$ to $2 \times 10^{4} \mathrm{kDa}$ ) and is synthesized on the surface of a variety of cells. HMW-HAs are space-filling molecules that hydrate tissues they not only play a role in cell adhesion but also are antiangiogenic, anti-inflammatory, and immunosuppressive [7]. HMW-HA can be degraded into lower molecular weight fragments (LMW-HA) by hyaluronidases, whose expression is elevated during the process of inflammatory responses, tumor development, and tissue injury $[3,8]$. Recent study shows that LMW-HA, not the native HMW-HA, can initiate inflammatory responses in dendritic cells in skin transplant rejection [9]. It has been reported that there are three receptors of LMW-HA, TLR2, TLR4 and CD44. Binding of LMW-HA to these receptors could activate immune cells and promote the production of different cytokines by macrophages, activated dendritic cells, and T cells [10-13].

Tumor cells have also been shown to produce hyaluronidases, which lead to HA degradation in the tumor surrounding environment [14]. Voelcker et al. suggested that LMW-HA in melanoma might promote tumor invasiveness by inducing MMP and cytokine expression, partly in a TLR4-dependent manner [15], providing new insights into the relationship between cancer and innate immunity. Moreover, Bourguignon et al. suggested that LMW-HA played an important role in CD44-TLR-associated AFAP-110-actin interaction and MyD88-NF- $\kappa$ B signaling, which was required for tumor cell behaviors [16]. Besides, LMW-HA inhibits colorectal carcinoma growth by decreasing tumor cell proliferation and stimulating immune response [17]. Bohm et al. suggested that strong stromal HA staining intensity was related to the progression and unfavorable outcome in differentiated thyroid carcinoma (DTC) patients including PTC [18]. However, little else is known about the function of LMW-HA in PTC development.

Key molecules such as chemokines/chemokine receptors not only attract leukocytes to local inflammatory sites but also directly enhance the survival, proliferation, and migration of tumor cells. The chemokine CXCL12 (also called stromal-derived factor-1) is an important chemokine that binds CXCR4/ CXCR7, playing important roles in promoting tumor cell proliferation and migration [19].

In this study, we investigated the roles of LMW-HA in the progression of PTC. We found that TLR4 was aberrantly overexpressed in PTC. Moreover, stimulation of LMW-HA induced CXCR7 expression in PTC cells via TLR4 signaling to promote the proliferation and migration of PTC cells. Furthermore, tumor-bearing mice and clinicopathology were used to verify that the LMW-HA/TLR4/CXCR7 pathway may be critical during the development of PTC, indicating LMW$\mathrm{HA}$ as a possible novel immunomodulatory therapy target for PTC treatment.

\section{Material and Methods}

2.1. Cell Lines. Human PTC cell line $\mathrm{K} 1$ was purchased from the American Type Culture Collection. Cell lines, W3, and TPC1 were kind gifts from Dr. Robert Gagel (MD Anderson Cancer Center, University of Texas, USA). All cells were cultured at $37^{\circ} \mathrm{C}$ and $5 \% \mathrm{CO}_{2}$. $\mathrm{K} 1$ cells were maintained in DMEM : Ham's F12 : MCDB 105 (2:1:1) (Invitrogen) and supplemented with $10 \%$ fetal bovine serum (FBS) (Invitrogen) and $100 \mu \mathrm{g} / \mathrm{mL}$ streptomycin (Invitrogen) and $100 \mathrm{U} / \mathrm{mL}$ penicillin (Invitrogen). W3 cells were maintained in RPMI 1640 (Invitrogen) with 10\% FBS (Invitrogen) and $100 \mu \mathrm{g} / \mathrm{mL}$ streptomycin (Invitrogen) and $100 \mathrm{U} / \mathrm{mL}$ penicillin (Invitrogen). TPC1 cells were maintained in DMEM (Invitrogen) with $10 \%$ FBS (Invitrogen) and $100 \mu \mathrm{g} / \mathrm{mL}$ streptomycin (Invitrogen) and $100 \mathrm{U} / \mathrm{mL}$ penicillin (Invitrogen).

2.2. Animals and Tumor Model. Female nude mice (6-8 week) were purchased from the Shanghai Laboratory Animal Center at the Chinese Academy of Sciences and housed in a specific pathogen-free facility at the Shanghai Jiao Tong University School of Medicine. All animal procedures were approved by the Animal Welfare \& Ethics Committee of Shanghai Jiao Tong University School of Medicine. Tumors were xenografted onto the left flank of mice through a subcutaneous injection of $6 \times 10^{6} \mathrm{~W} 3$ cells in $50 \mu \mathrm{L}$ of phosphate buffered saline (PBS). Mice were intratumorally injected with LMW-HA (4,900 Da, JIANGSU HAIHUA BIOTECH CO, China, $400 \mu \mathrm{g} / \mathrm{kg}$ ) or the same volume of DMSO every other day. Tumors were measured with a caliper every fourth day and tumor volumes were calculated using the formula (length $\times$ width $\left.^{2}\right) / 2$. When maximum diameters of tumors reached about $1.0 \mathrm{~cm}$, mice were euthanized. Tumors were removed and weighed. CXCR7 expression in tumor tissues was analyzed by immunohistochemistry.

2.3. Patients and Specimens. This study was approved by the Medical Ethics Committee of The First Affiliated Hospital of Bengbu Medical College and all works were conducted in accordance with the Declaration of Helsinki. All participants gave informed written consent before participating in this study. PTC samples were collected from 135 patients undergoing curative-intent surgery at the Department of Surgery, The First Affiliated Hospital of Bengbu Medical College between 2001 and 2011. There were also 56 normal thyroid tissue samples adjacent to papillary thyroid carcinoma (used as controls). The histologic sections were reviewed by two expert pathologists to verify the histologic diagnosis. None of the patients had received any preoperative treatment. Tumors were staged according to the American Joint Committee on Cancer (AJCC) pathologic tumor-node-metastasis (TNM) classification. 
2.4. Western Blot Analysis. PTC cell lines were lysed with RIPA Lysis Buffer (Beyotime, China) supplemented with protease inhibitor Cocktail (AppliChem, Germany). Protein concentration in the postnuclear lysates was measured by BCA Protein Assay Kit (Beyotime, China) and equal amounts of protein lysates $(60 \mu \mathrm{g})$ were loaded on $10 \%$ SDS-PAGE. Gels were transferred to nitrocellulose using iBlot Dry Blotting System (Invitrogen, USA). Filters were blocked with 5\% dry skimmed milk and blotted with the specific primary antibodies: mouse monoclonal antibody to TLR4 (Abcam, England), TLR2 (eBioscience, USA), or CD44 (eBioscience, USA). Blots were then incubated with the appropriate HRP-conjugated secondary antibody (Beyotime, China), and signals were detected by the WestPico chemiluminescence system (Pierce). Filters were stripped for 10 min with ReBlot Plus Strong Antibody Stripping Solution (Millipore).

2.5. Flow Cytometric Assay. For in vitro studies of CXCR7 and CXCR4 expression, all cell lines were cultured in medium containing 2\% FBS. After $12 \mathrm{~h}$, W3 cells were treated with LMW-HA for $24 \mathrm{~h}$. Then cells were trypsinized and incubated for $1 \mathrm{~h}$ with a monoclonal anti-human CXCR7 antibody (R\&D systems, USA) or CXCR4 antibody (BD Biosciences, USA) and analyzed using a flow cytometry (BD Aria).

2.6. Cell Transfection. siRNA sequences (TLR4: $5^{\prime}$-GAGCCGCUGGUGUAUCUUU-3' ${ }^{\prime}$, TLR4-KD; CXCR7: 5' -CCGUUCCCUUCUCCAUUAU-3', CXCR7-KD; Scrambled siRNA: 5' -AGGACTGAGTGTACCGTCT-3', Scram) were designed into shRNA and inserted into pGPU6/GFP/Neo vector (GenePharma, Shanghai, China) under U6 promoter. Cells resistant to G418 ( $800 \mu \mathrm{g} / \mathrm{mL})$ were selected and expanded for further study. The depletion of endogenous TLR4 or CXCR7 by the shRNA was confirmed by immunoblot.

2.7. Cell Proliferation Assay. W3 cells were cultured in 96-well plates at an initial density of 2,000 cells per well, in $100 \mu \mathrm{L}$ of $1 \%$ FBS-medium with or without addition of LMW-HA $(100 \mathrm{ng} / \mathrm{mL})$ for indicated times. Cell proliferation was determined using a WST-1 Kit (Beyotime, China). Each experimental condition was sampled in triplicate and the experiments were repeated three times.

2.8. Apoptosis Assay. W3 cells were incubated in 1\% FBSmedium with or without addition of LMW-HA for 24 hours and incubated for $30 \mathrm{~min}$ at room temperature with $0.5 \mathrm{mg} /$ $\mathrm{mL}$ propidium iodide (PI, eBioscience, USA) and annexin VFITC (eBioscience, USA). Then cells were analyzed with flow cytometry. Each experiment was repeated three times.

2.9. Migration Experiments. W3 cells were resuspended in 1\% FBS-medium at $5 \times 10^{5}$ cells $/ \mathrm{mL}$ and seeded into the upper chambers of Transwell inserts (Millipore). 1\% FBS-medium was added to the lower chambers, with or without addition of CXCL12 $(100 \mathrm{ng} / \mathrm{mL})$. After incubation with LMW-HA, the nonmigrated cells were removed from the upper surface of the filters, and the migrated cells, adherent to the lower surface, were counted (Ten high-power fields/well). Each experiment was repeated three times.
2.10. Immunohistochemistry Assay. Sections were subjected to routine deparaffination and rehydration. Antigen retrieval was achieved by microwaving in $0.01 \mathrm{~mol} / \mathrm{L}$ citrate buffer for $10 \mathrm{~min}$ and then cooled for $30 \mathrm{~min}$. The endogenous peroxidase activity was inhibited by incubation with $3 \%$ hydrogen peroxide in methanol for $20 \mathrm{~min}$ and nonspecific binding was blocked with $5 \%$ bovine serum albumin in PBS at room temperature. After three PBS washes, the specimens were incubated overnight at $4^{\circ} \mathrm{C}$ with murine anti-human TLR4 and CXCR7 monoclonal antibodies. After incubation with rat anti-mouse-IgG2b-horseradish peroxidase, signal was developed with 3, 30-diaminobenzidine tetrahydrochloride in Tris- $\mathrm{HCl}$ buffer ( $\mathrm{pH}$ 7.6) containing $0.02 \%$ hydrogen peroxide. The sections were then counterstained with hematoxylin and mounted. Negative controls were performed by replacing the primary antibody with nonspecific IgG at the same concentration.

\subsection{Interpretation and Evaluation of Immunohistochemical} Results. Immunostaining was independently examined by two clinical pathologists who were unaware of the patient outcome. For each sample, five high-power fields $(100 \times)$ were randomly selected. Staining intensity and percentage of positive tumor cells were assessed. The extent of the staining was categorized into five semiquantitative classes based on the percentages of positive tumor cells: $0(<5 \%$ positive cells), 1 (6-25\% positive cells), 2 ( $26-50 \%$ positive cells), 3 (51-75\% positive cells), and 4 ( $>75 \%$ positive cells). The intensity of cytoplasmic and membrane staining was also determined semiquantitatively on a scale of $0-3$ as follows: 0 (negative), 1 (weakly positive), 2 (moderately positive), and 3 (strongly positive). A consensus score was assigned for each section after discussion and careful review of all slides by the two pathologists. Multiplication of the intensity and the percentage scores gave rise to the final staining score: negative $(0),+(1-4),++(5-8)$, and $+++(9-12)$. For statistical analysis, tumors having a final staining score of negative or + , which showed a weak or moderate/strong immunoreactivity, were grouped into a low expression group and were compared to tumors with scores of ++ or +++ as the high expression group.

2.12. Statistical Analysis. Differences were evaluated using the Statistical Package for Social Science software (version 16.0, SPSS Inc., Chicago, IL). The association of staining intensity with clinicopathologic patterns was assessed with the Chi square test and two-sided Fisher's exact test to determine the significance of the difference between the covariates. All measurement data are presented as mean \pm SEM. Statistical significance was evaluated by one-way ANOVA, followed by the least significant difference (LSD) test. $P$ values $<0.05$ were considered to be statistically significant.

\section{Results}

3.1. TLR4 Is Highly Expressed in PTC Tissues and Cell Lines. It has been shown that lymphocytic infiltration presented in or around PTC tissues, which mediated local inflammatory responses and affected the progression of PTC [4]. In sites of 


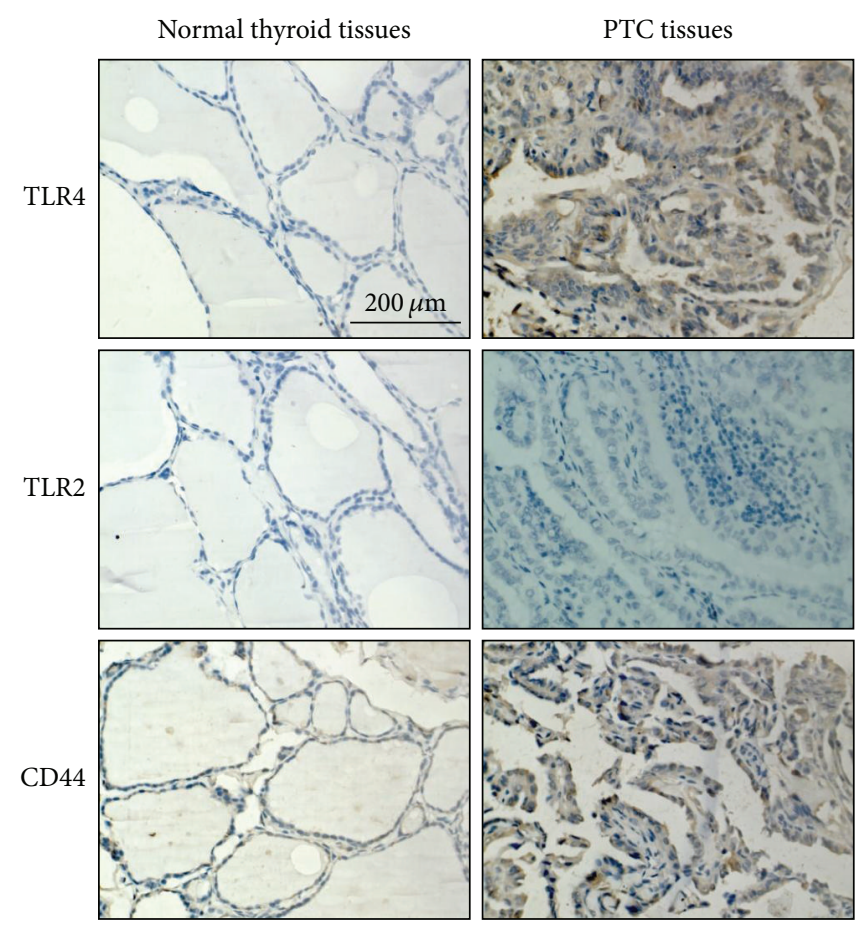

(a)
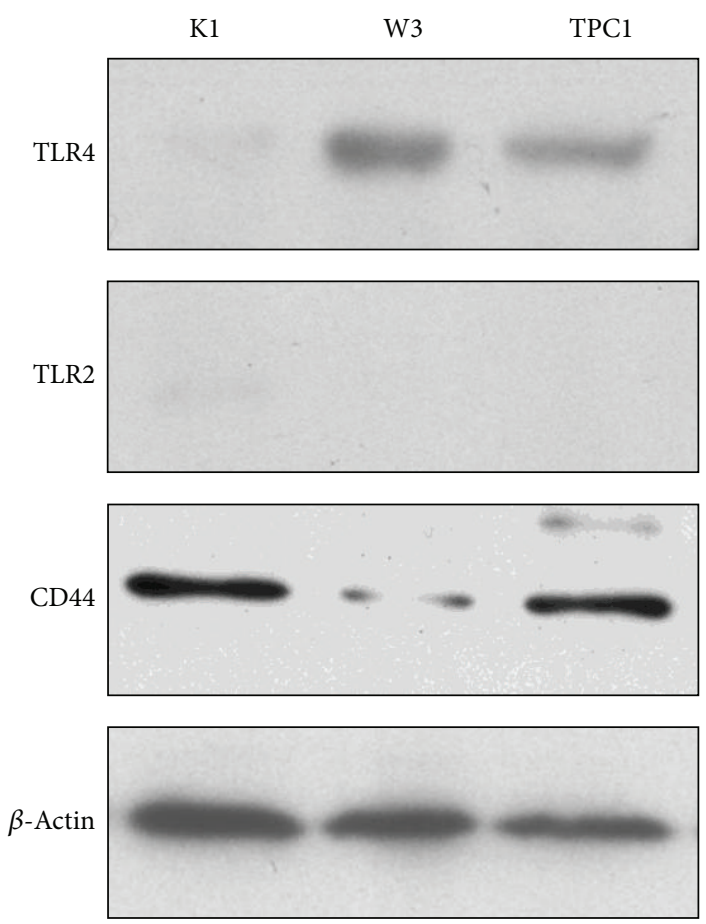

(b)

FIGURE 1: Increased TLR4 expression in PTC tissues and cell line W3. (a) Representative examples of IHC staining analyses of TLR4, TLR2, and CD44 in human normal thyroid tissues and PTC tissues (original magnification 400×). (b) Immunoblot analysis of the expression of TLR4, TLR2, and CD44 on 3 human PTC cell lines. Representative results are shown.

inflammation, HMW-HA may be degraded into LMW-HA, which in return activates immune responses $[3,11]$. It has been reported that strong stromal HA staining intensity is related to progression and unfavourable outcome in thyroid carcinoma patients [18]. To investigate whether LMW-HA played a role in the development of PTC, we assessed the expression levels of three LMW-HA receptors, TLR2, TLR4, and CD44, in PTC tissues and three different human PTC cell lines (K1, W3, and TPC1). Immunohistochemistry analysis showed that TLR4 was highly expressed in PTC tissues compared to normal thyroid tissues (Figure 1(a), Table 1, $P<$ $0.001)$; TLR2 was virtually undetectable $(<10 \%$ of cells) in both normal thyroid tissues and PTC tissues; CD44 was expressed in most of normal thyroid tissues (51 of 56) and PTC tissues (128 of 135) (data not shown). These data demonstrate that TLR4 is aberrantly overexpressed in PTC, suggesting that LMW-HA/TLR4 may participate in the development of PTC. At the same time, western blot analysis indicated that TLR4 was highly expressed on W3 cells, moderately expressed on TPCl cells, and low or negatively expressed on K1 cells; CD44 was weakly expressed on W3 cells and strongly expressed on K1 and TPC1 cells; while TLR2 expression could not be detected on three of these cell lines (Figure 1(b)). As CD44 expression did not show difference between normal thyroid tissues and PTC tissues, TLR $4{ }^{\text {high }} \mathrm{CD} 44^{\text {low }}$ PTC cell line, W3 cells were chosen for this study thereafter to exclude the possible effects of LMW-HA/CD44 signal on tumor progression.
3.2. LMW-HA Promotes Proliferation and Migration of W3 Cells via TLR4. Then we treated W3 cells with LMW-HA and determined the effects of LMW-HA on W3 cell apoptosis, proliferation, and migration. Stimulation of LMW-HA significantly enhanced the proliferation of W3 cells (Figure 2(a)) but did not induce apoptosis of W3 cells (Figure 2(b)). Moreover, LMW-HA significantly promoted the migration of W3 cells in the presence of CXCL12 (Figure 2(c)). Next we investigated if LMW-HA promotes proliferation and migration of W3 cells via the receptor, TLR4. When TLR4 expression was knocked down by shRNA (Figure 2(d)), LMW-HA induced proliferation and migration of W3 cells were mostly abolished (Figures 2(e) and 2(f)). In addition, we further stimulated TLR4 negative K1 cells with LMW-HA, and the data showed that LMW-HA did not promote the proliferation and migration of K1 cells (see Supplemental Figures (a) and (b) available online at http://dx.doi.org/10.1155/2013/712561). Collectively, these data suggest that LMW-HA promotes the proliferation and migration of W3 cells through activating TLR4 signal pathway.

3.3. LMW-HA Elevates CXCR7 Expression to Promote Proliferation and Migration of W3 Cells. To determine how LMWHA promotes proliferation and migration of W3 cells, downstream molecules of TLR4 signal pathway, CXCR4 and CXCR7 expression were examined in W3 cells treated with or without LMW-HA. Neither CXCR4 nor CXCR7 was 
TABLE 1: Correlation of TLR4 and CXCR7 expression with clinicopathologic features in PTC.

\begin{tabular}{|c|c|c|c|c|c|c|c|}
\hline \multirow{2}{*}{ Clinicopathologic parameters } & \multirow{2}{*}{ Case no. } & \multicolumn{2}{|c|}{ TLR4 expression } & \multirow{2}{*}{$P$ value } & \multicolumn{2}{|c|}{ CXCR7 expression } & \multirow{2}{*}{$P$ value } \\
\hline & & Low & High & & Low & High & \\
\hline Total cases & 135 & 64 & 71 & $53 \%$ & 102 & 33 & $24 \%$ \\
\hline \multicolumn{8}{|l|}{ Age } \\
\hline$\leq 60$ & 55 & 27 & 28 & \multirow{2}{*}{$P=0.745$} & 38 & 19 & \multirow{2}{*}{$P=0.080$} \\
\hline$>60$ & 80 & 37 & 43 & & 64 & 15 & \\
\hline \multicolumn{8}{|l|}{ Tissue type } \\
\hline Normal tissue & 56 & 55 & 1 & \multirow{2}{*}{$P=0.000$} & 55 & 1 & \multirow{2}{*}{$P=0.000$} \\
\hline Carcinoma & 135 & 64 & 71 & & 102 & 33 & \\
\hline \multicolumn{8}{|l|}{ Sex } \\
\hline Male & 65 & 33 & 32 & \multirow{2}{*}{$P=0.451$} & 48 & 17 & \multirow{2}{*}{$P=0.656$} \\
\hline Female & 70 & 31 & 39 & & 54 & 16 & \\
\hline \multicolumn{8}{|l|}{ Tumor size } \\
\hline$\leq 5 \mathrm{~cm}$ & 58 & 39 & 19 & \multirow{2}{*}{$P=0.000$} & 53 & 5 & \multirow{2}{*}{$P=0.000$} \\
\hline$>5 \mathrm{~cm}$ & 77 & 25 & 52 & & 49 & 28 & \\
\hline \multicolumn{8}{|l|}{ TNM stage } \\
\hline I & 4 & 4 & 0 & \multirow{4}{*}{$P=0.000$} & 4 & 0 & \multirow{4}{*}{$P=0.005$} \\
\hline II & 65 & 39 & 26 & & 57 & 8 & \\
\hline III & 38 & 7 & 31 & & 24 & 14 & \\
\hline IV & 28 & 14 & 14 & & 17 & 11 & \\
\hline \multicolumn{8}{|l|}{ Histologic grade } \\
\hline I & 8 & 7 & 1 & \multirow{3}{*}{$P=0.000$} & 8 & 0 & \multirow{3}{*}{$P=0.002$} \\
\hline II & 109 & 56 & 53 & & 86 & 23 & \\
\hline III & 18 & 1 & 17 & & 8 & 10 & \\
\hline \multicolumn{8}{|l|}{ Lymph nodemetastasis } \\
\hline Negative & 76 & 50 & 26 & \multirow{2}{*}{$P=0.000$} & 70 & 6 & \multirow{2}{*}{$P=0.000$} \\
\hline Positive & 59 & 14 & 45 & & 32 & 27 & \\
\hline \multicolumn{8}{|l|}{ Distant metastasis } \\
\hline Negative & 108 & 56 & 52 & \multirow{2}{*}{$P=0.039$} & 89 & 19 & \multirow{2}{*}{$P=0.000$} \\
\hline Positive & 27 & 8 & 19 & & 13 & 14 & \\
\hline
\end{tabular}

expressed in W3 cells, whereas exposing W3 cells to LMWHA induced significant CXCR7 expression (Figure 3(a)). In contrast to CXCR7 expression alterations, LMW-HA had no effect on CXCR4 expression in W3 cells (Figure 3(b)). To investigate the role of TLR4 in LMW-HA-mediated CXCR7 expression, we knocked down TLR4 in W3 cells. Then LMW-HA-mediated CXCR7 expression was totally inhibited (Figure 3(c)). Next we assessed whether upregulation of CXCR7 expression was responsible for LMW-HA induced proliferation and migration of W3 cells. We found that knockdown of CXCR7 (Figure 3(d)) indeed blocked the proliferation and migration alterations in W3 cells induced by LMW-HA (Figures 3(e) and 3(f)). Moreover, LMW-HA also did not upregulate CXCR7 expression in TLR4 negative K1 cells. Taken together, these findings suggest that LMW-HA/ TLR4-induced CXCR7 expression significantly promotes PTC cell proliferation and migration.

3.4. Stimulation of W3 Cells by LMW-HA Promotes Tumor Growth in Adult Nude Mice. To substantiate the effects of LMW-HA on tumor growth, female BALB/c nude mice were subcutaneously injected with W3 cells and treated with or
TABLE 2: CXCR7 expression in W3 cell transplanted tumor tissues of nude mice.

\begin{tabular}{lcccc}
\hline Group & $n$ & \multicolumn{2}{c}{ CXCR7 expression } & $P$ value \\
& & Low & High & \\
\hline LMW-HA & 6 & 2 & 4 & $P=0.002$ \\
DMSO & 6 & 6 & 0 & \\
\hline
\end{tabular}

without LMW-HA. The volumes of the tumor masses formed in LMW-HA treatment groups were larger than those of tumors from the control treatment groups (Figure 4(a)). To determine the effect of LMW-HA/TLR4/CXCR7 pathway on tumor growth in vivo, TLR4 or CXCR7 was inhibited with shRNA in W3 cells. Tumor growth was substantially inhibited in TLR4-KD and CXCR7-KD group in contrast to scrambled siRNA group in the presence of LMW-HA (Figure 4(b)), suggesting that LMW-HA may promote growth of W3-derived PTC model tumors in vivo through TLR4/CXCR7 pathway. Then immunohistochemistry analysis demonstrated that CXCR7 expression was significantly higher in tumor masses treated with LMW-HA in contrast to that of control treatment groups (Figure 4(c); Table $2, P=0.002$ ). Knockdown of 


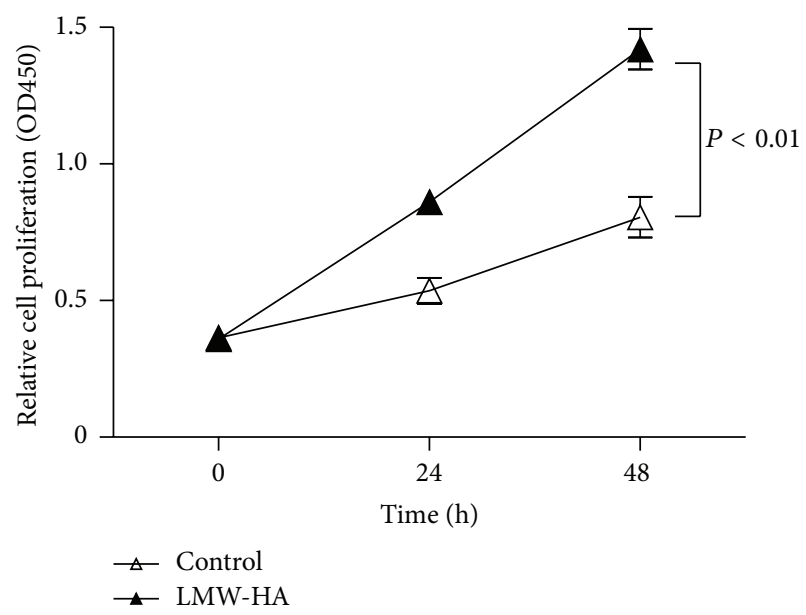

(a)

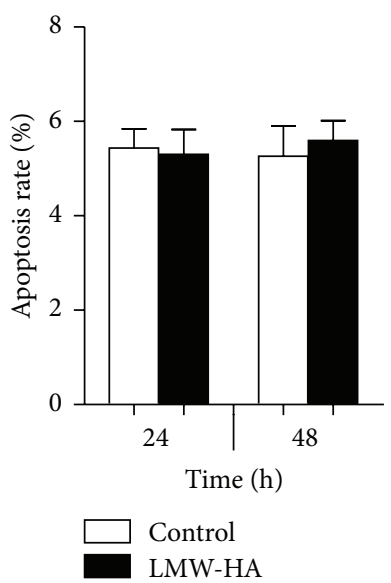

(b)

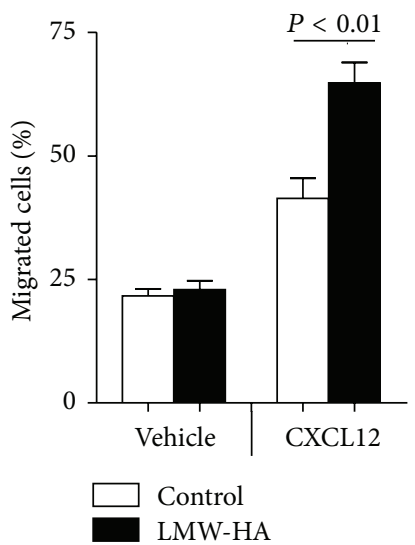

(c)

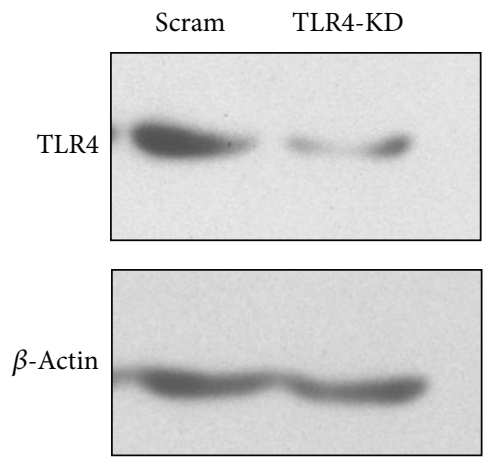

(d)

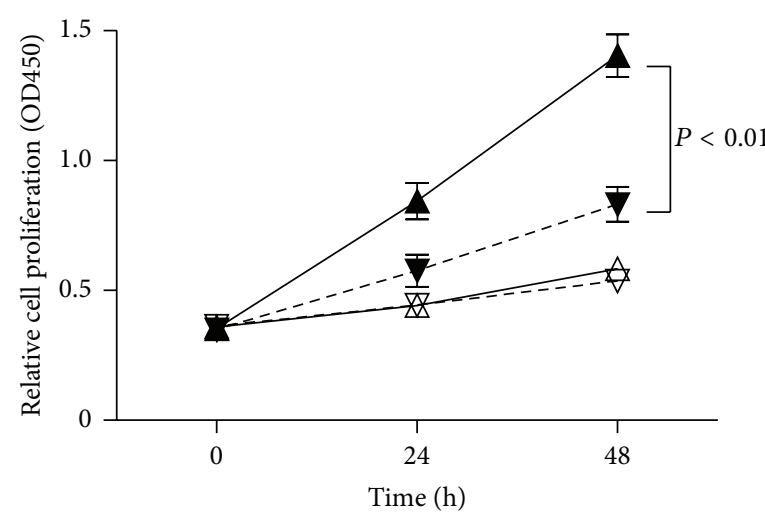

$\triangle$ Scram + vehicle

$\_$Scram + LMW-HA

$-\nabla-$ TLR4-KD + vehicle

- - TLR4-KD + LMW-HA

(e)

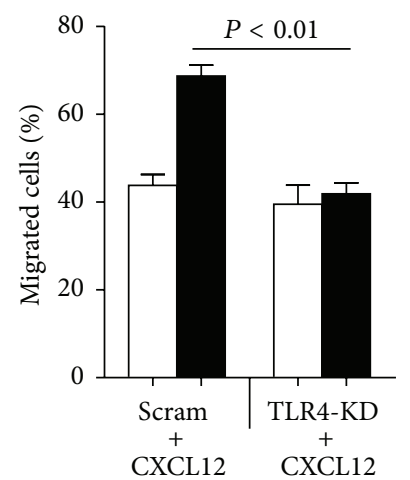

Control

LMW-HA

(f)

FIGURE 2: LMW-HA promotes W3 cell proliferation and migration via TLR4. (a) W3 cells were seeded into 96-well plates (2,000 cells/well) and treated with or without LMW-HA. Cell proliferation was analyzed with WST-1 Kit. Data are mean \pm SEM for three independent experiments. (b) W3 cells were treated with or without LMW-HA for 24 hours and stained with annexin V and PI. Data are mean \pm SEM for three independent experiments. (c) W3 cells were seeded into the upper chambers of transwell inserts treated with or without LMW-HA and in the presence or absence of CXCL12 in the lower chambers. Migrated cells were determined. Data are mean \pm SEM for three independent experiments. (d) W3 cells were transfected with scrambled shRNA (Scram) or TLR4 shRNA-expressing constructs (TLR4-KD) and subjected to immunoblot analysis. (e) Scram-W3 cells and TLR4-KD W3 cells were seeded into 96 well plates and treated with or without LMWHA $(100 \mu \mathrm{g} / \mathrm{mL})$ for $24 \mathrm{~h}$; cell proliferation was analyzed. Data are mean \pm SEM for three independent experiments. (f) Scram-W3 cell and TLR4-KD W3 cell migration to CXCL12 treated with or without LMW-HA was determined. Data are mean \pm SEM for three independent experiments.

TLR4 inhibited LMW-HA-induced expression of CXCR7 in tumor masses, indicating that CXCR7 was induced by LMWHA in tumor tissue through TLR4 and might play important roles in tumorigenicity.

\subsection{Expression of TLR4 or CXCR7 Is Associated with Tumor} Size and Lymph Node Metastasis. To further determine whether LMW-HA/TLR4/CXCR7 pathway plays a role in PTC progression, we investigated the clinicopathologic significance of TLR4 and CXCR7 expression using immunohistochemistry in human PTC tissues. TLR4 and CXCR7 exhibited mostly cytoplasmic and plasmalemmal staining in carcinoma tissues (Figures 1(a) and 5). Normal tissue adjacent to tumor cells showed negative or occasionally weak staining that was mostly cytoplasmic (Figures 1(a) and 5). The differences in expression of the two molecules between carcinoma tissues and normal thyroid tissues were all found to be statistically significant (Table 1; TLR4, $P<0.001$; CXCR7, $P<$ 0.001). As shown in Table 1, tumor size tended to be larger in cases with high rather than low expression of TLR4 $(P<$ $0.001)$ and CXCR7 $(P<0.001)$. There is a statistically significant correlation between TNM stage and TLR4 expression 

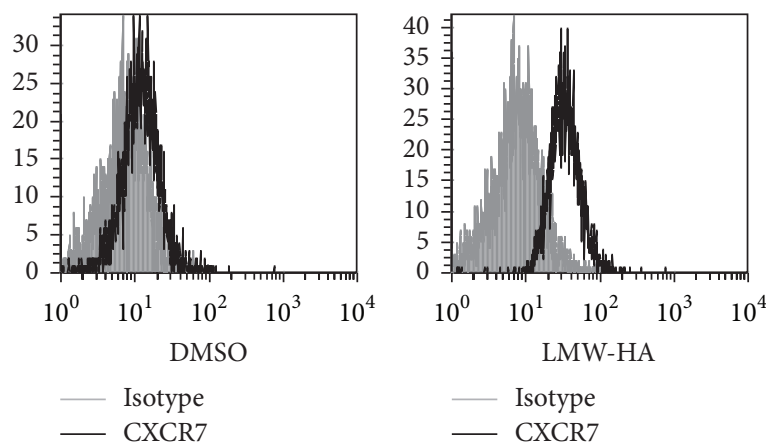

(a)
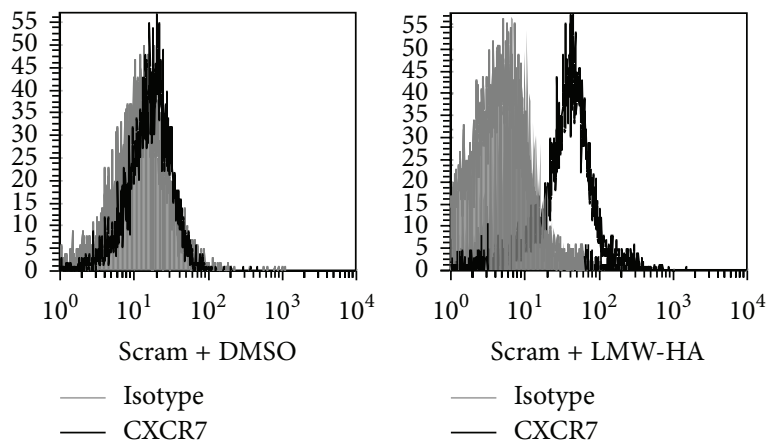
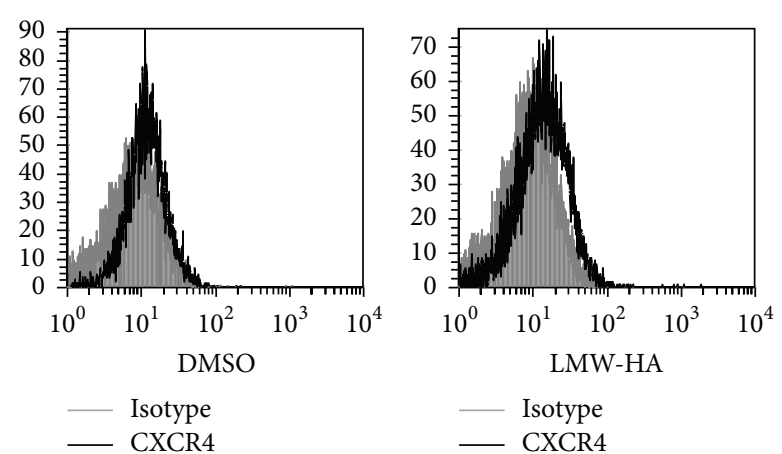

(b)
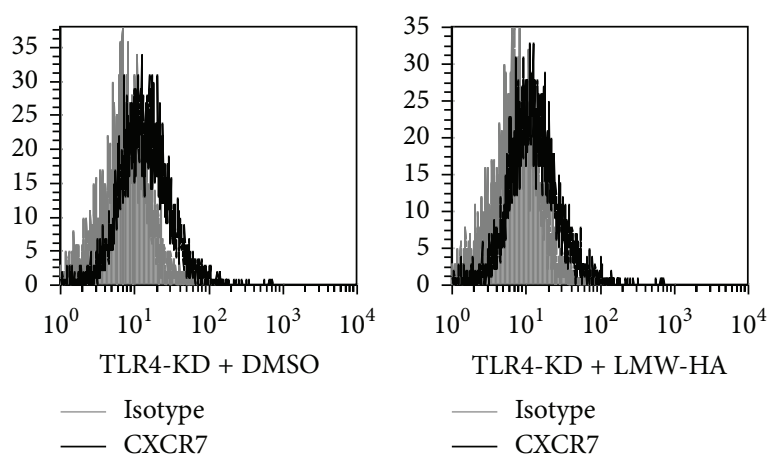

(c)

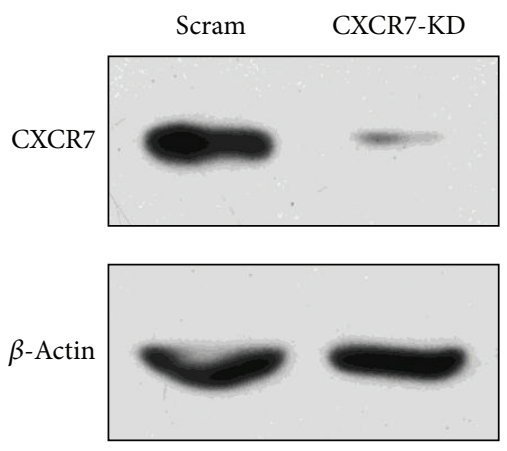

(d)

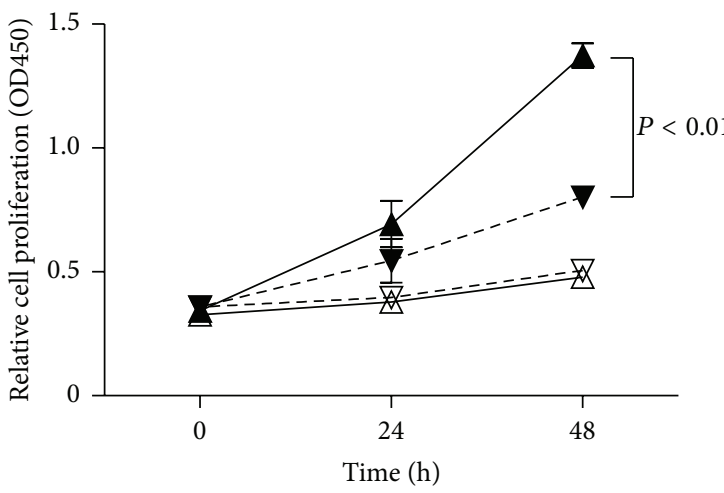

$\triangle$ Scram + vehicle

$\neg$ Scram + LMW-HA

$-\nabla-$ CXCR7-KD + vehicle

- - CXCR7-KD + LMW-HA

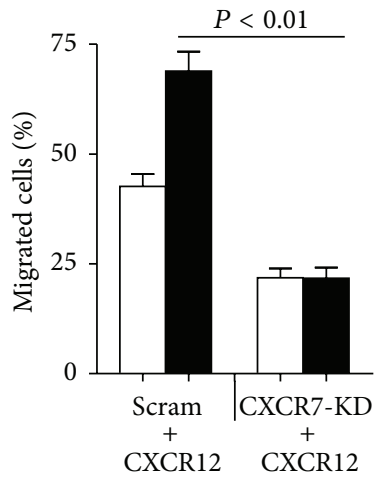

Control

LMW-HA

(f)

FIGURE 3: LMW-HA upregulates CXCR7 to promote W3 cell proliferation and migration. ((a)-(b)) W3 cells were incubated with LMWHA $(100 \mu \mathrm{g} / \mathrm{mL})$ for $24 \mathrm{~h}$; representative flow cytometric analysis of CXCR7 (a) or CXCR4 (b) expression was shown. (c) Scram-W3 cells and TLR4-KD W3 cells were treated with or without LMW-HA $(100 \mu \mathrm{g} / \mathrm{mL})$ for $24 \mathrm{~h}$; representative flow cytometric analysis of CXCR7 expression was shown. (d) W3 cells were transfected with scrambled shRNA (Scram) or CXCR7 shRNA-expressing constructs (CXCR7-KD), and subjected to immunoblot analysis. (e) Scram-W3 cells and CXCR7-KD W3 cells were seeded into 96 well plates (2,000 cells/well) and treated with or without LMW-HA. Cell proliferation was analyzed. Data are mean \pm SEM for three independent experiments. (f) ScramW3 cell and CXCR7-KD W3 cell migration to CXCL12 treated with or without LMW-HA was determined. Data are mean \pm SEM for three independent experiments.

$(P<0.001)$ or CXCR7 expression $(P=0.005)$. The increased expression is significantly associated with advanced histological grade (TLR4, $P=0.001$; CXCR7, $P=0.002$ ). At the same time, the incidence of lymph node metastasis tended to be higher in patients with PTC with high rather than low expression of TLR4 $(P<0.001)$ or CXCR7 $(P<0.001)$. In addition, the incidence of distant metastasis tended to be higher in patients with PTC with high rather than low expression of TLR4 $(P=0.039)$ or CXCR7 $(P<0.001)$. There were no statistically significant differences in these molecules with 


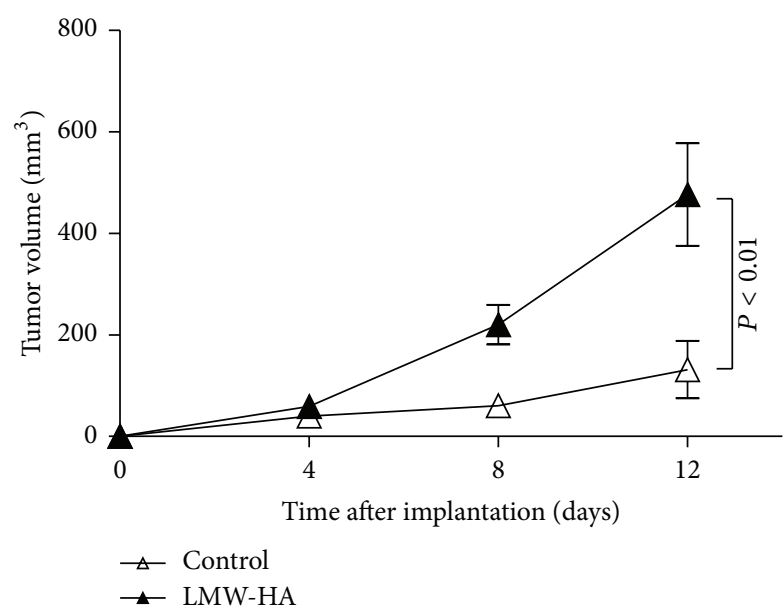

(a)
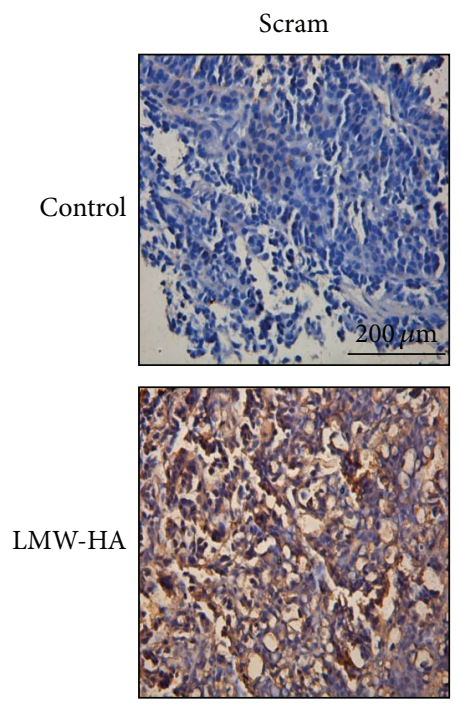

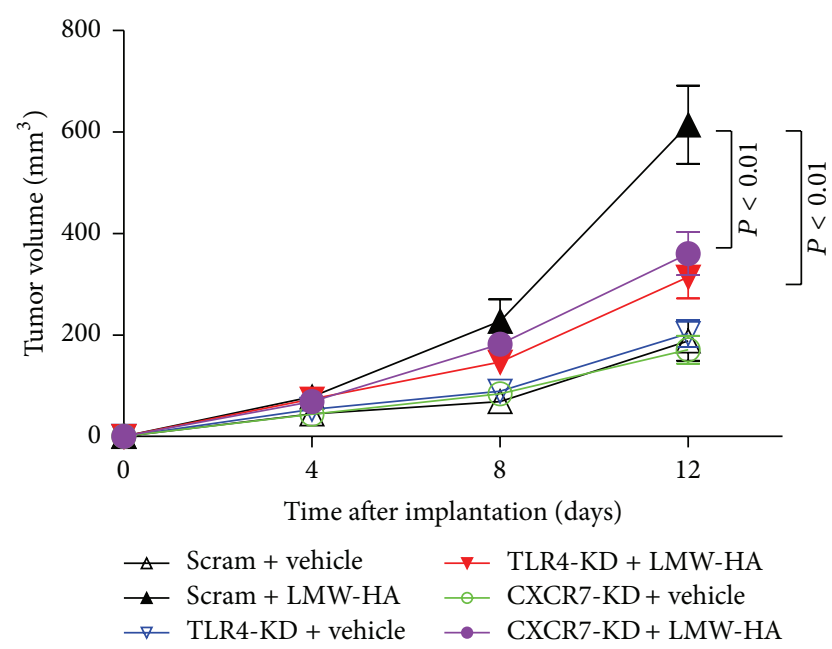

(b)
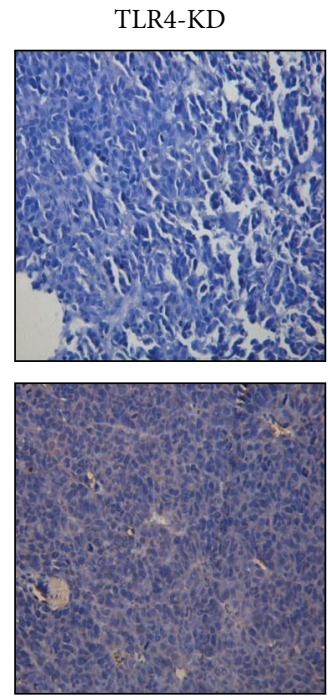

(c)
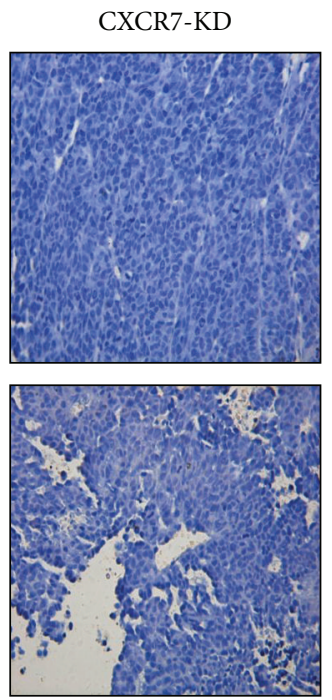

FIGURE 4: LMW-HA enhances the tumorigenicity of W3 cell line via TLR4/CXCR7 pathway. (a) W3 cells $\left(6 \times 10^{6}\right.$ cell/mouse) were injected subcutaneously into the flanks of nude mice, and mice were intratumorally injected with LMW-HA ( $400 \mu \mathrm{g} / \mathrm{kg})$ or the same volume of DMSO every other day. Tumors were measured with a caliper every fourth day. When tumor maximum diameter reached about $1.0 \mathrm{~cm}$, mice were euthanized and tumors were removed and weighed. The volumes of the tumor masses formed in LMW-HA treatment groups and control treatment groups were determined. (b) Scram-W3 cells, TLR4-KD W3 cells, and CXCR7-KD W3 cells were injected subcutaneously into the flanks of nude mice, and mice were intratumorally injected with LMW-HA (400 $\mu \mathrm{g} / \mathrm{kg})$ or the same volume of DMSO every other day. Tumor volumes were determined and shown. (c) CXCR7 expression of tumors was analyzed by immunohistochemistry (original magnification $400 \times)$. These results were representative of three independent experiments.
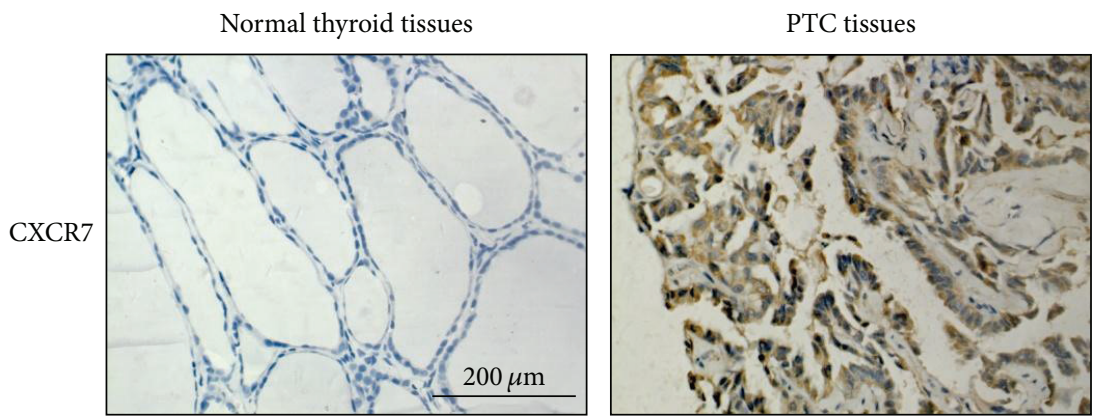

FIGURE 5: Increased expression of CXCR7 in PTC tissues. Representative examples of immunohistochemical staining of CXCR7 in normal thyroid tissues and PTC tissues (original magnification 400×). Representative results are shown. 
regard to patient age and sex. All these data indicate that expression of TLR4 or CXCR7 is associated with PTC tumor size and lymph node metastasis.

\section{Discussion}

Metastases, rather than primary tumors, are responsible for most cancer deaths. This process requires tumor cells to acquire the ability of proliferation, antiapoptosis, migration, and invasion. The presence of central neck lymph node metastases in PTC is known as an independent risk factor for recurrence. Our data showed that LMW-HA induced CXCR7 upregulation in PTC cells through TLR4 signaling, which promoted PTC cell line W3 proliferation and migration. Likewise, LMW-HA could also promote W3 cell proliferation in nude mice. Furthermore, higher rates of TLR4 and CXCR7 expression were found in human PTC tissues than in normal thyroid tissues, indicating that expression of these two molecules is associated with increased carcinoma growth and metastasis potential in human PTC.

In sites of inflammation or tissue injury, HA, ubiquitous in the extracellular matrix, is broken down into LMW-HA that has been reported to activate immunocompetent cells. For instance, it induces inflammatory chemokine and cytokine expression in macrophages [20]. Black et al. demonstrated a novel CD44 and MyD88 independent pathway for HA fragments to activate macrophage production of interferon- $\beta$ via TLR4-TRIF-TBK1-IRF3 [21]. Stimulation of TLRs by LMW-HA induces self-defense mechanisms in vaginal epithelium [22]. LMW-HA increases the self-defense of skin epithelium by induction of $\beta$-defensin 2 via TLR2 and TLR 4 [13]. LMW-HA and HMGB1 act as innate immune cytokinelike signals with the potential to modulate chondrocyte differentiation and function in OA progression via MyD88dependent TLR2/TLR4 signaling [23]. Recently, LMW-HA has been shown to be associated with tumor invasiveness and metastasis [24]. Our data in this study have unraveled the crucial mechanisms underlying the promoting effect of inflammation-derived-LMW-HA signaling on the metastatic potential of PTC cells. A marked increase of CXCR7 expression was induced in a TLR4 positive PTC cell line W3, in response to LMW-HA. Knockdown of TLR4 in W3 cells has provided evidence that TLR4 is essential for LMW-HA-induced CXCR7 expression. Simultaneously, we established LMWHA-W3 tumor-bearing mice model to further determine the function of the LMW-HA/TLR4/CXCR7 pathway in PTC.

CD44 is a primary cell-surface HA receptor. Binding of HA to CD44 plays roles in cell adhesion, immune responses, and tumor development. Although it has been reported that HA-CD44 signaling promotes the progression of several cancers, such as breast cancer [25], colorectal carcinoma [17], fibrosarcoma [26], and glioblastoma multiforme [27], in this study we found that CD44 was overexpressed in both normal tissue and PTC tissue and overexpression of CD44 was not relevant to progression of PTC. Further in vitro study may be needed to investigate the effect of CD44 on the proliferation and migration of PTC cell lines.
TLR4 expressed on tumor cells has been found to contribute to tumor progression by promoting tumor cell proliferation, apoptosis resistance, and tumor evasion from immune attack $[28,29]$. LPS was released from the damaged cells or from bacteria in tumor tissues. Once LPS binds to TLR4, two signaling pathways are activated: a MyD88-dependent pathway and a MyD88-independent pathway [30, 31]. Based on studies using macrophages, these pathways are responsible for the expression of proinflammatory cytokines [32-34]. Clinical and experimental studies indicate that TLR4 plays a significant role in connecting inflammation and cancer invasion and progression, but the exact mechanism is still not clear. The chemokine CXCL12/SDF-1 and its receptor, CXCR4, have been implicated in invasion, survival, and proliferation of carcinoma cells [35]. Recently, CXCR7 was identified as a second receptor for CXCL12 [36, 37]. Though, some results have indicated that CXCR7 functions as a decoy receptor [38], growing evidence suggested that CXCR7 significantly increases cell proliferation and elevates cellular adhesion property in some conditions [36, 38-41]. We observed that CXCR7 induced by LMW-HA could promote metastasis of PTC cell line W3. However, LMW-HA had no effect on CXCR4 expression. In animal model, differences in CXCR7 expression in tumor masses between the two groups were statistically significant. In addition, the incidence of lymph node metastasis and distant metastasis tended to be higher in patients with PTC with high rather than low expression of TLR4 or CXCR7. Conclusively, the LMWHA/TLR4/CXCR7 pathway is involved in the development of PTC, suggesting that LMW-HA/TLR4 signaling may be an effective immunomodulatory therapeutic target in PTC.

\section{Conclusion}

In conclusion, we demonstrated that LMW-HA could promote the development of PTC. After binding to TLR4, LMWHA activated TLR4 signal pathway to promote PTC cell proliferation and migration through upregulation of CXCR7 expression. We also suggested that aberrant expression of TLR4 and CXCR7 in PTC was associated with poor progression of PTC. Therefore, taking the LMW-HA/TLR4/CXCR7 pathway as the potential immunomodulatory therapy target may be a promising approach for PTC treatment.

\section{Conflict of Interests}

All authors have no conflict of interests.

\section{Acknowledgments}

The authors thank Dr. Robert Gagel (MD Anderson Cancer Center, University of Texas, USA) for gifts of PTC cell lines W3 and TPC1. They also thank Drs. Xiaonan Zhao, Lijun Meng, Zhaogeng Cai, Zhenzhong Feng, Yi Zhang, and Jiefang Huang for their kind assistance. This work was supported by the Strategic Priority Research Program of the Chinese Academy of Sciences (XDA01040000), Ministry of Science and Technology of China (2011CB966200), National Natural 
Science Foundation of China (81202113, 81071748, and 30873045), the Anhui Province Natural Science Foundation (Grant nos. 1208085QH157 and 11040606 M206).

\section{References}

[1] B. Jankovic, K. T. Le, and J. M. Hershman, "Clinical Review: Hashimoto's thyroiditis and papillary thyroid carcinoma: is there a correlation?" Journal of Clinical Endocrinology and Metabolism, vol. 98, pp. 474-482, 2013.

[2] D. S. McLeod, A. M. Sawka, and D. S. Cooper, "Controversies in primary treatment of low-risk papillary thyroid cancer," The Lancet, vol. 381, pp. 1046-1057, 2013.

[3] J. Modi, A. Patel, R. Terrell, R. M. Tuttle, and G. L. Francis, “Papillary thyroid carcinomas from young adults and children contain a mixture of lymphocytes," Journal of Clinical Endocrinology and Metabolism, vol. 88, no. 9, pp. 4418-4425, 2003.

[4] J. D. French, Z. J. Weber, D. L. Fretwell, S. Said, J. P. Klopper, and B. R. Haugen, "Tumor-associated lymphocytes and increased FoxP3+ regulatory $\mathrm{T}$ cell frequency correlate with more aggressive papillary thyroid cancer," Journal of Clinical Endocrinology and Metabolism, vol. 95, no. 5, pp. 2325-2333, 2010.

[5] T. C. Laurent and J. R. E. Fraser, "Hyaluronan," FASEB Journal, vol. 6, no. 7, pp. 2397-2404, 1992.

[6] C. B. Underhill, "The interaction of hyaluronate with the cell surface: the hyaluronate receptor and the core protein," Ciba Foundation symposium, vol. 143, pp. 87-100, 1989.

[7] R. Stern, "Hyaluronan catabolism: a new metabolic pathway," European Journal of Cell Biology, vol. 83, no. 7, pp. 317-325, 2004.

[8] R. Stern, "Devising a pathway for hyaluronan catabolism: are we there yet?" Glycobiology, vol. 13, no. 12, pp. 105R-115R, 2003.

[9] B. M. Tesar, D. Jiang, J. Liang, S. M. Palmer, P. W. Noble, and D. R. Goldstein, "The role of hyaluronan degradation products as innate alloimmune agonists," The American Journal of Transplantation, vol. 6, no. 11, pp. 2622-2635, 2006.

[10] D. Jiang, J. Liang, J. Fan et al., "Regulation of lung injury and repair by Toll-like receptors and hyaluronan," Nature Medicine, vol. 11, no. 11, pp. 1173-1179, 2005.

[11] A. F. Chambers, A. C. Groom, and I. C. MacDonald, "Dissemination and growth of cancer cells in metastatic sites," Nature Reviews Cancer, vol. 2, no. 8, pp. 563-572, 2002.

[12] K. A. Scheibner, M. A. Lutz, S. Boodoo, M. J. Fenton, J. D. Powell, and M. R. Horton, "Hyaluronan fragments act as an endogenous danger signal by engaging TLR2," Journal of Immunology, vol. 177, no. 2, pp. 1272-1281, 2006.

[13] S. Gariboldi, M. Palazzo, L. Zanobbio et al., "Low molecular weight hyaluronic acid increases the self-defense of skin epithelium by induction of $\beta$-defensin 2 via TLR 2 and TLR4," Journal of Immunology, vol. 181, no. 3, pp. 2103-2110, 2008.

[14] D. Liu, E. Pearlman, E. Diaconu et al., "Expression of hyaluronidase by tumor cells induces angiogenesis in vivo," Proceedings of the National Academy of Sciences of the United States of America, vol. 93, no. 15, pp. 7832-7837, 1996.

[15] V. Voelcker, C. Gebhardt, M. Averbeck et al., "Hyaluronan fragments induce cytokine and metalloprotease upregulation in human melanoma cells in part by signalling via TLR4," Experimental Dermatology, vol. 17, no. 2, pp. 100-107, 2008.

[16] L. Y. W. Bourguignon, G. Wong, C. A. Earle, and W. Xia, "Interaction of low molecular weight hyaluronan with CD44 and tolllike receptors promotes the actin filament-associated protein
110 -actin binding and MyD88-NFאB signaling leading to proinflammatory cytokine/chemokine production and breast tumor invasion," Cytoskeleton, vol. 68, no. 12, pp. 671-693, 2011.

[17] L. Alaniz, M. Rizzo, M. Malvicini et al., "Low molecular weight hyaluronan inhibits colorectal carcinoma growth by decreasing tumor cell proliferation and stimulating immune response," Cancer Letters, vol. 278, no. 1, pp. 9-16, 2009.

[18] J. Bohm, L. Niskanen, R. Tammi et al., "Hyaluronan expression in differentiated thyroid carcinoma," Journal of Pathology, vol. 196, no. 2, pp. 180-185, 2002.

[19] H. Xu, Q. Wu, S. Dang et al., "Alteration of CXCR7 expression mediated by TLR4 promotes tumor cell proliferation and migration in human colorectal carcinoma," PLoS ONE, vol. 6, no. 12, Article ID e27399, 2011.

[20] A. Sattar, P. Rooney, S. Kumar et al., "Application of angiogenic oligosaccharides of hyaluronan increases blood vessel numbers in rat skin," Journal of Investigative Dermatology, vol. 103, no. 4, pp. 576-579, 1994.

[21] K. E. Black, S. L. Collins, R. S. Hagan, M. J. Hamblin, Y. Chan-Li, R. W. Hallowell et al., "Hyaluronan fragments induce IFNbeta via a novel TLR4-TRIF-TBK1-IRF3-dependent pathway," Journal of Inflammation, vol. 10, aryicle 23, 2013.

[22] G. F. Dusio, D. Cardani, L. Zanobbio et al., "Stimulation of TLRs by LMW-HA induces self-defense mechanisms in vaginal epithelium," Immunology and Cell Biology, vol. 89, no. 5, pp. 630639, 2011

[23] R. Liu-Bryan and R. Terkeltaub, "Chondrocyte innate immune myeloid differentiation factor 88-dependent signaling drives procatabolic effects of the endogenous toll-like receptor 2/tolllike receptor 4 ligands low molecular weight hyaluronan and high mobility group box chromosomal protein 1 in mice," Arthritis and Rheumatism, vol. 62, no. 7, pp. 2004-2012, 2010.

[24] R. I. Cordo Russo, G. Ernst, S. Lompardía et al., "Increased hyaluronan levels and decreased dendritic cell activation are associated with tumor invasion in murine lymphoma cell lines," Immunobiology, vol. 217, pp. 842-850, 2012.

[25] P. Heldin, K. Basu, B. Olofsson, H. Porsch, I. Kozlova, and K. Kahata, "Deregulation of hyaluronan synthesis, degradation and binding promotes breast cancer," Journal of Biochemistry, vol. 154, no. 5, pp. 395-408, 2013.

[26] D. Nikitovic, K. Kouvidi, N. K. Karamanos, and G. N. Tzanakakis, "The roles of hyaluronan/RHAMM/CD44 and their respective interactions along the insidious pathways of fibrosarcoma progression," BioMed Research International, vol. 2013, Article ID 929531, 12 pages, 2013.

[27] L. V. De Souza, A. Matta, Z. Karim, J. Mukherjee, X. S. Wang, O. Krakovska et al., "Role of moesin in hyaluronan induced cell migration in glioblastoma multiforme," Molecular Cancer, vol. 12, article 74, 2013.

[28] K. H. Kim, M. S. Jo, D. S. Suh, M. S. Yoon, D. H. Shin, J. H. Lee et al., "Expression and significance of the TLR4/MyD88 signaling pathway in ovarian epithelial cancers," World Journal of Surgical Oncology, vol. 10, article 193, 2012.

[29] L. Wang, Y. Zhao, J. Qian, L. Sun, Y. Lu, H. Li et al., “Toll-like receptor-4 signaling in mantle cell lymphoma: effects on tumor growth and immune evasion," Cancer, vol. 119, pp. 782-791, 2012.

[30] M. Yamamoto, S. Yamazaki, S. Uematsu et al., "Regulation of Toll/IL-1-receptor-mediated gene expression by the inducible nuclear protein I $\kappa \mathrm{B} \zeta$," Nature, vol. 430, no. 6996, pp. 218-222, 2004 . 
[31] M. Szajnik, M. Szczepanski, M. Czystowska, E. Elishaev, M. Mandapathil, E. Nowak-Markwitz et al., "Expression and signaling of Toll-like receptor 4 (TLR4) and MyD88 in ovarian carcinoma cells," Journal of Clinical Oncology, vol. 27, Article ID e16508, 2009.

[32] D. Zhang, Y. Li, Y. Liu, X. Xiang, and Z. Dong, "Paclitaxel ameliorates lipopolysaccharide-induced kidney injury by binding myeloid differentiation protein-2 to block Toll-like receptor 4mediated nuclear factor-kappaB activation and cytokine production," Journal of Pharmacology and Experimental Therapeutics, vol. 345, pp. 69-75, 2013.

[33] H. Hu, Z. Li, X. Zhu, R. Lin, J. Lin, J. Peng et al., "Gua Lou Gui Zhi decoction suppresses LPS-induced activation of the TLR4/ NF-kappaB pathway in BV-2 murine microglial cells," International Journal of Molecular Medicine, vol. 31, pp. 1327-1332, 2013.

[34] L. Palová-Jelínková, K. Dáňová, H. Drašarová, M. Dvořák, D. P. Funda, P. Fundová et al., "Pepsin digest of wheat gliadin fraction increases production of IL-1beta via TLR4/MyD88/TRIF/ MAPK/NF-kappaB signaling pathway and an NLRP3 inflammasome activation," PLoS ONE, vol. 8, Article ID e62426, 2013.

[35] A. Müller, B. Homey, H. Soto et al., "Involvement of chemokine receptors in breast cancer metastasis," Nature, vol. 410, no. 6824, pp. 50-56, 2001.

[36] K. E. Luker, S. A. Lewin, L. A. Mihalko et al., "Scavenging of CXCL12 by CXCR7 promotes tumor growth and metastasis of CXCR4-positive breast cancer cells," Oncogene, vol. 31, pp. 4750-4758, 2012.

[37] X. Sun, G. Cheng, M. Hao et al., "CXCL12/CXCR4/CXCR7 chemokine axis and cancer progression," Cancer and Metastasis Reviews, vol. 29, no. 4, pp. 709-722, 2010.

[38] S. Rajagopal, J. Kim, S. Ahn et al., " $\beta$-Arrestin: but not G protein-mediated signaling by the "decoy" receptor CXCR7," Proceedings of the National Academy of Sciences of the United States of America, vol. 107, no. 2, pp. 628-632, 2010.

[39] K. Zheng, H.-Y. Li, X.-L. Su et al., “Chemokine receptor CXCR7 regulates the invasion, angiogenesis and tumor growth of human hepatocellular carcinoma cells," Journal of Experimental and Clinical Cancer Research, vol. 29, no. 1, article 31, 2010.

[40] K. Hattermann, J. Held-Feindt, R. Lucius et al., "The chemokine receptor CXCR7 is highly expressed in human glioma cells and mediates antiapoptotic effects," Cancer Research, vol. 70, no. 8, pp. 3299-3308, 2010.

[41] N. Maishi, N. Ohga, Y. Hida et al., "CXCR7: a novel tumor endothelial marker in renal cell carcinoma," Pathology International, vol. 62 , no. 5, pp. 309-317, 2012. 


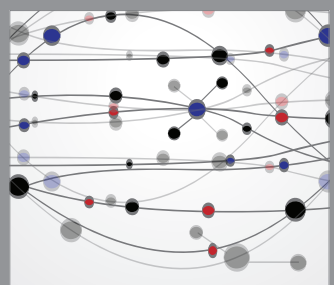

The Scientific World Journal
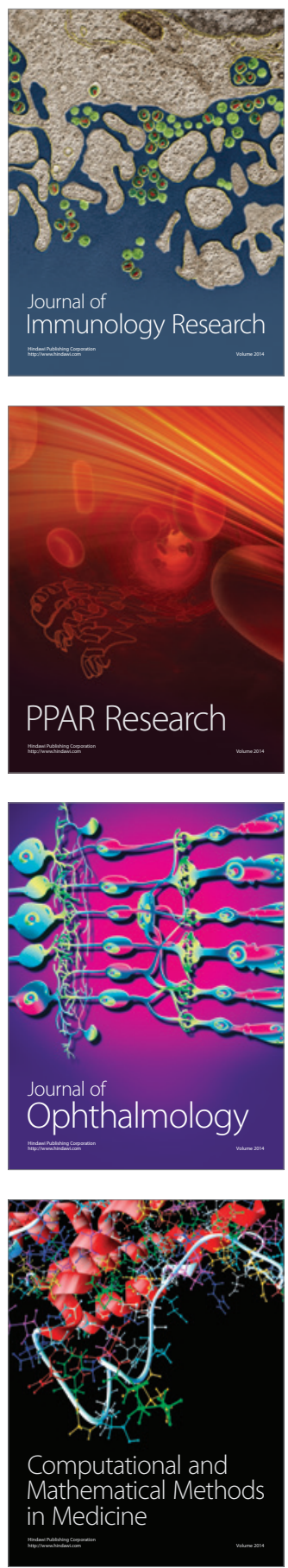

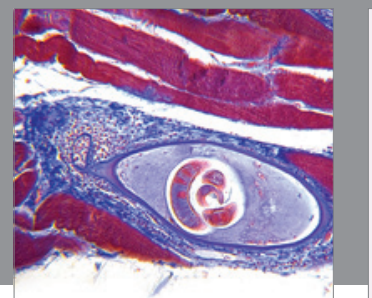

Gastroenterology

Research and Practice
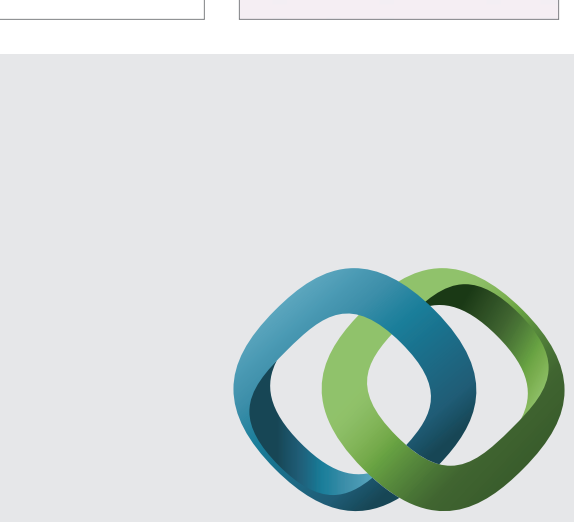

\section{Hindawi}

Submit your manuscripts at

http://www.hindawi.com
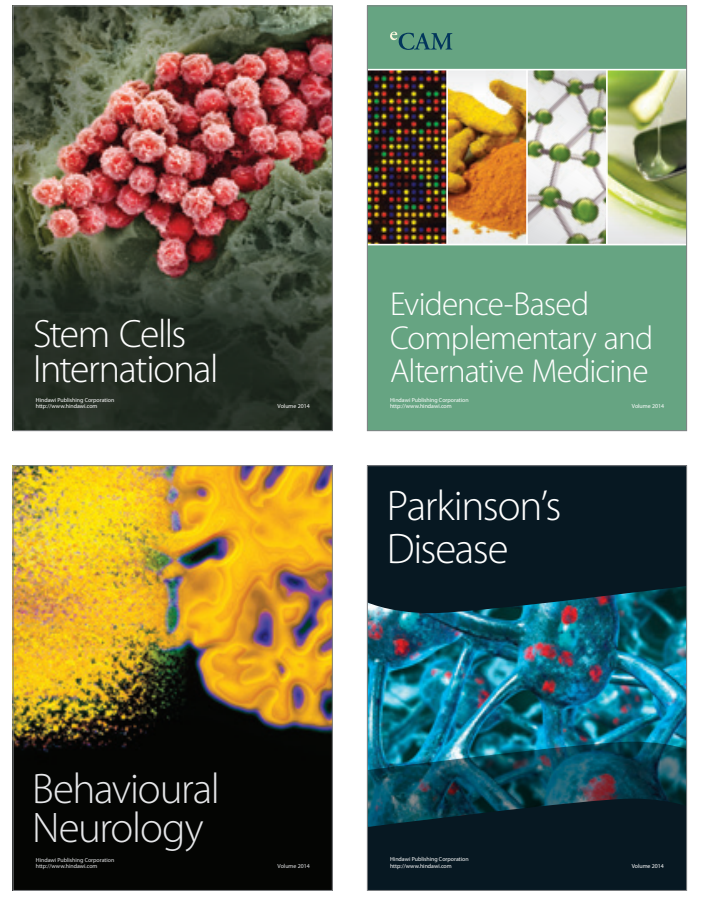
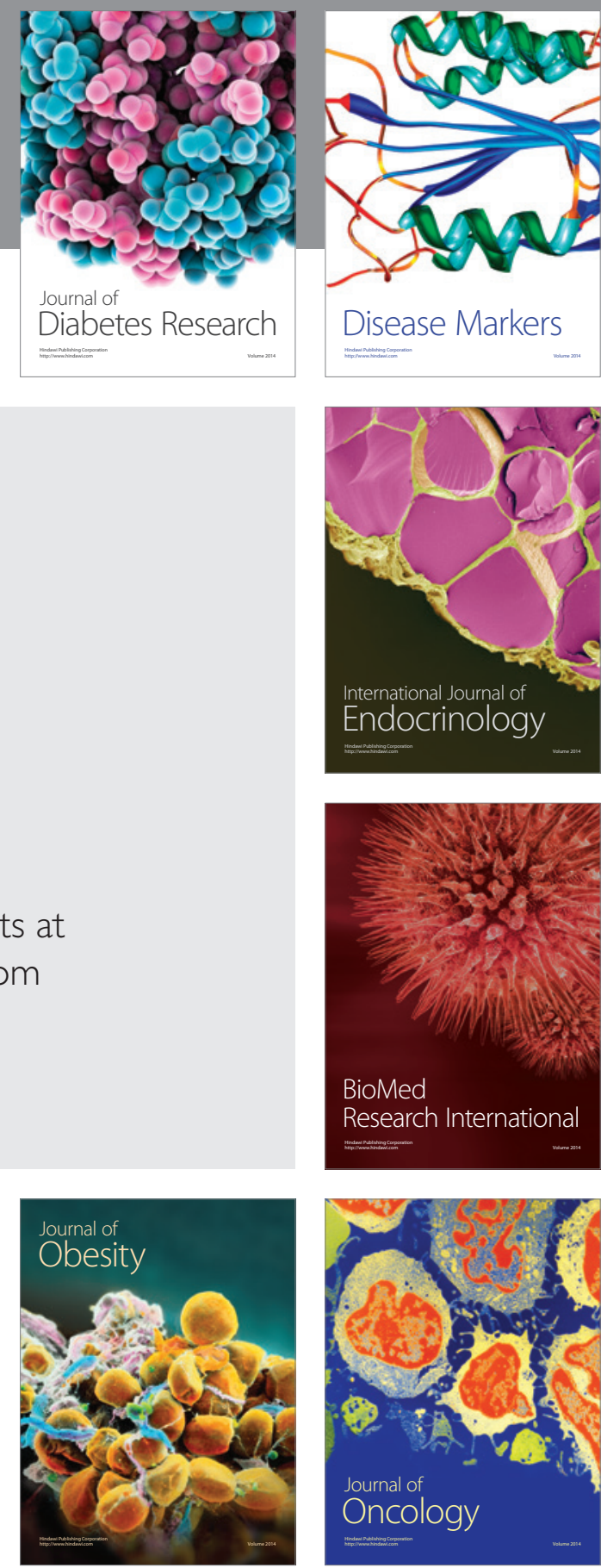

Disease Markers
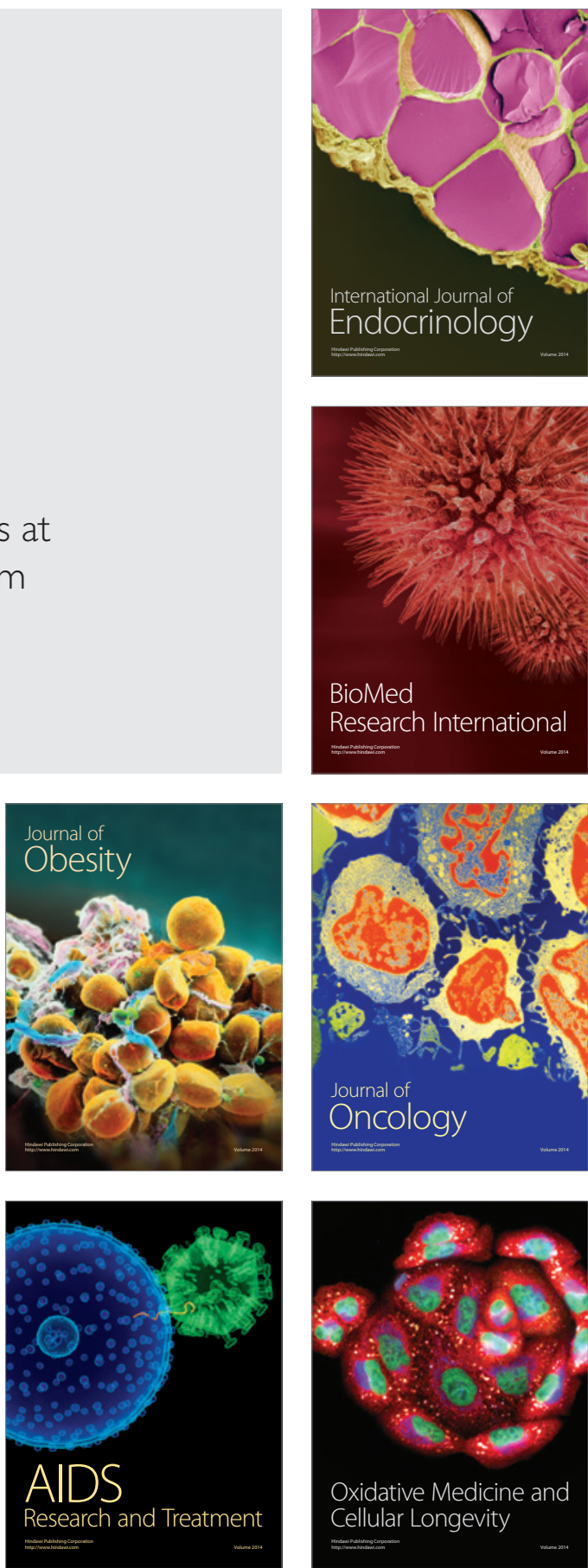